\title{
Undergraduate nursing students' placement in speciality clinical areas: understanding the concerns of the student and registered nurse.
}

Key words: clinical placement, undergraduate nursing students, speciality clinical areas, qualitative inquiry, nurse education

Introduction

Student nurses in Australia are regularly placed in acute clinical areas providing them with clinical experience to link theory with real patient situations. Specialist clinical areas such as day oncology and renal dialysis often exclude students on the basis that their clinical area may not be able to meet normal clinical expectations, including holistic care of four to six patients with minimal direction from the registered nurse. However, specialist clinical areas provide students with unique learning experiences. This paper reports on an evaluation of speciality clinical placements for student nurses with an aim to increase our understanding of this type of placement.

Methods

Semi-structured audiotaped interviews were undertaken with seven third year final semester students and 13 registered nurses working with the third year students. All interviews were transcribed and a thematic analysis conducted.

Findings

Key themes from the students and registered nurses were knowledge and preparedness for specialist placement, team work and being included and customising learning needs.

Conclusion

Speciality placements provide a valuable experience for the undergraduate nurse including opportunities to see excellence in team work, communication and assessment as well as identifying future intention to become an oncology or renal specialist nurse. 


\section{INTRODUCTION}

The clinical placement of undergraduate nursing students in acute hospital areas prepares students for clinical work as a registered nurse. The clinical placement should enhance the student's engagement in a clinical situation and increase their ability to apply clinical reasoning to a situation (Benner, Sutphen, Leonard, \& Day, 2010). The clinical placement should provide an environment where the student can contextualise the skills learned at university; for example, assessment and communication skills, and also the patient's response and interaction in a clinical situation (Benner, et al., 2010). Providing the link between theory and clinical practice, the clinical placement provides students with the opportunities to integrate theory with practice. However, clinical areas continue to report a lack of 'practice readiness' of graduate registered nurses. This highlights the need to evaluate the clinical placement to improve our understanding of the quality of placement areas (Romyn, Linton, Giblin, Hendrickson, Limacher, Murray et al., 2009).

In Australia, two to four week clinical placements have routinely been offered to students in generalist areas, medical and surgical wards and in high acuity areas, which include critical care, emergency and theatre. Acute care speciality areas such as ambulatory oncology and renal dialysis units in Brisbane have not regularly offered undergraduate placement. This placement may provide students with a deeper understanding of these specific areas as well as generic skills as a registered nurse. Acute speciality areas have identified a need for future graduate nurses to increase their staffing levels, which may be improved by encouraging student nurses' exposure to these clinical areas. This paper explores placement of students in a speciality area, evaluating a four week placement from the perspective of the students themselves and the registered nurses supervising them.

\section{BACKGROUND}

Clinical placement of undergraduate nursing students aims to provide students with a link between theory and clinical practice. The student is exposed to a range of clinical scenarios, all with an undetermined trajectory unlike the class room setting. These clinical situations, under the guidance of registered nurses, provide the student with opportunities to develop clinical reasoning (Benner, et al., 2010). The registered nurse also provides both supervision and guidance on the procedures and expectations of their respective clinical areas. As the student nurses progress through their undergraduate degree they typically build their 
knowledge from general to high acuity nursing areas. The student begins to link the theory with clinical practice and the general patient; however, in many cases, they do not gain specialist knowledge discrete to particular areas.

The student is often unprepared for the depth of knowledge and skills required to work in these specialist areas (Newton \& McKenna, 2008). Students also lack the understanding of the procedures and the problems unique to patients in these specialist areas (Beecroft, Santner, Lacy, Kunzman, \& Dorey, 2006; Neill \& Taylor, 2002). For example, the administration of chemotherapy and renal dialysis are specific to day oncology and renal dialysis areas. However could these placement areas provide a range of different skills? Research has shown that in these areas registered nurses are the major source of patient education providing information on disease and treatment (Gambles, Wilkinson, \& Dissanayake, 2003). The nurse's educative role with patients may suggest transferrable skills for student education. The registered nurses in clinical areas are also noted to have excellent assessment and patient communication skills both of which provide registered nurses with the skills needed to provide support and supervision of student nurses (Fukui, Ogawa, Ohtsuka, $\&$ Fukui, 2009). Anecdotally nursing staff have reflected that another benefit of specialist areas is that there is a high nurse: patient ratio. This higher nurse: patient ratio may enhance the ability of the registered nurse to supervise students in speciality areas.

The goal of clinical placement is to provide students with the opportunity to apply theory to the clinical area (Wade \& Hayes, 2010). In specialist clinical areas students are able to apply specific theory related to that area. Although students do not have specific theory related to day oncology and renal dialysis procedures, the clinical preceptors are experienced clinicians who are able to supervise the student in relation to specific procedures within the area. Skills, although not generic nursing skills, can still build the students clinical reasoning around holistic patient care. Skills such as patient assessment, communication, patient education and counselling are skills utilised frequently in these speciality areas as well as being fundamental to nursing practice (Fukui, et al., 2009).

Previous concerns from the staff in day oncology and renal dialysis relate to the students scope of practice and role of the student during specific procedures such as dialysis and chemotherapy administration (ANMC, 2012). It is therefore an Australian Nursing and Midwifery Council (ANMC) requirement that the student will only be able to observe some 
clinical procedures in these areas. However students are still developing useful knowledge and clinical reasoning related to caring for patients with these types of diseases. Other clinical skills such as portacath access and line priming for dialysis can be taught as competency based learning as long as students are closely supervised by skilled registered nurses this enhances their learning outcomes from these areas.

The supervision of students in the clinical area has been noted to influence students' growth and clinical preparedness (Brammer, 2008). Brammer (2008) explains the importance of registered nurses allowing time for student supervision, encouraging questions and allowing students time to critically think through the clinical situation. In these speciality areas there is often time during procedures for education of both the patient and student, providing students with both the skills of patient education and the opportunity to form links between theory and practice. Although these different clinical areas must embrace different learning objectives for students, guidelines can increase the registered nurses' understanding of student expectations (Brammer, 2008; Wade \& Hayes, 2010).

The culture of the ward area and attitudes of the registered nurses have been identified as having an influence on student learning (Brammer, 2008; Levett-Jones, 2005). Previous research exploring personality types of oncology and palliative care nursing staff revealed that they tended to be extraverted, empathetic, trusting, open and group oriented, all of which are excellent attributes for teaching and supervising student nurses (Fukui, et al., 2009; Gambles, et al., 2003). The registered nurses in day oncology and renal dialysis areas have often worked in other acute wards areas prior to specialising in either oncology or dialysis, providing them with a range of clinical skills to augment their supervision of students. Specialist ward areas often have smaller numbers of registered nurses and therefore supervision of students or new graduates can become a burden to staff if not managed well (Brammer, 2008).

One of the differences between general wards and day oncology and renal dialysis areas is that students have little understanding of the specialist areas prior to clinical placement. Students attending placement in other speciality areas such as operating theatre, intensive care and accident and emergency may also lack an understanding of the role of registered nurses in these areas. However medical programs on television often provide visibility to the expectations and cultural aspects of these critical care areas. Day oncology and renal dialysis 
are not visible at all to the student nurse and therefore students are not able to identify as easily with these particular areas. Whilst there has been research into student nurse placement in general areas (Calpin-Davies, 2003; Edwards, Smith, Courtney, Finlayson, \& Chapman, 2004), this evaluation aims to explore the placement of students in specialty areas, specifically day oncology and renal dialysis where undergraduate students are not normally placed.

\section{METHODS}

This evaluation will provide an insight into both the students' and registered nurses' experience of undergraduate student nurse clinical placements in day oncology and renal dialysis units. Interviews were conducted with both the students and the registered nurses to provide an insight into the specialty clinical placement for third year students completing a Bachelor of Nursing course.

\section{$\underline{\text { Sample }}$}

A convenience sample of student nurses completing four week clinical placement in a renal dialysis unit and an ambulatory day oncology unit were invited to participate in the evaluation $(\mathrm{N}=10)$. Students were selected to complete clinical placement in these areas, day oncology and renal dialysis in two ways, student preference and academic merit. Only two students were able to attend placement in day oncology and four in renal dialysis each clinical placement. Semi-structured interviews were conducted with student nurses $(n=7)$ who volunteered to participate in the study. Three students declined to participate explaining they were too busy to come in for the interview. Registered nurses who worked one to one with the student nurses in these clinical areas were invited to participate $(\mathrm{N}=13)$. All registered nurses approached agreed to be involved in the study. The nature of these specific units in Australia means they have smaller numbers of registered nurses working in them. All participants used a pseudonym. The research was considered as exempt from needing ethical approval. It was identified as teaching evaluation by the senior ethics manager and data collected as part of quality assurance for the purposes of informing and improving teaching practices. The students and registered nurses were provided with an information sheet, explaining the teaching evaluation, interview process, right to withdraw and the analysis process.

\section{$\underline{\text { Data collection }}$}


Interviews were conducted with the students in a quiet room at the university at a time convenient for the student. Interviews were conducted by the main researcher with the registered nurses at their place of work during their shift; the nurse educator of the unit relieved the registered nurses thus allowing time for the interview. Some of the registered nurse interviews were completed as a focus group to enable the registered nurses to feel at ease with the interview process. The interviews were 15 to 30 minutes in length. The interview questions asked for the student to reflect about their experience and how they found placement. The questions for the registered nurse asked them to reflect on the experience of working with students. See table 1 for question details.

Insert table 1

\section{Data analysis}

All interviews were audiotaped and transcribed verbatim. Transcripts were analysed using inductive qualitative techniques that comprised a multi-phase thematic analysis (Braun \& Clarke, 2006; Ryan \& Bernard, 2003). The first step in the analysis was the reading and reviewing of the narrative data by the first and second researcher. During this stage phrases were underlined in the first step to identifying themes. Recurring themes within one transcript and across the data set as a whole were then grouped using a cut and sort method (Miles \& Huberman, 1994). Key phrases were then grouped into broad categories and shared collectively with the other researcher to gain consensus. A thematic map was built to see links between developing themes. Further redefining of themes occurred as patterns within the data became visible. Transcripts were revisited to identify missing phrases as new themes developed. The final coding decisions were based on full agreement from the researchers. Participants reviewed and verified their transcripts and resultant themes to ensure rigour (Grbich, 1999; Silverman, 2003). All data are confidential and were anonymously analysed.

\section{FINDINGS}

Analysis of the data revealed several main themes emerging from both the student and the registered nurse point of view. The themes identified were levels of knowledge for specialist placement, team work and being included, shaping learning needs and value of specialist areas.

\section{Knowledge and preparedness for specialist placement}


The students identified that they lacked knowledge and preparation for these areas. They all discussed how their lack of knowledge reduced their ability to prepare and increased their nervousness about going to these areas; however they also described how they were welcomed into the areas.

I had absolutely no idea what I was to expect. Probably a bad thing, because I couldn't really prepare. I didn't know what we'd be doing, what we'd be allowed to do, so I didn't know what to look up. Nervous as all hell ... Pleasantly surprised. It was really nice there. Student renal dialysis

The students going into the day oncology area discussed how they thought they understood oncology nursing, but found they were not prepared for the speed and difference of the day oncology area.

I was quite nervous because it was a speciality area, but excited as I preferenced to go to that area. ... we realised it was a day clinic ... it was a shock because we were ready for a ward situation and it was nothing like it. Student day oncology

The students also described their initial impressions of the specialist areas, comparing them with general areas. They stated that in general wards registered nurses are often not prepared for students, the wards are busy and students must just fit in. In the speciality areas the students described being welcomed and orientated to the area which they described as being a pleasant change.

Well on the first day we met with the educator and she did a little orientation ... talked about our goals and stuff ... what she was expecting and some policies with us... the nurse I was with was very welcoming on the first day, she was really good to me. Student day oncology

We felt comfortable arriving; they were expecting us unlike some previous places where they weren't actually expecting students. They had an information sheet all ready to give to us. Student renal dialysis

The registered nurses also spoke of being notified of students attending placement and preparing themselves for students. The registered nurses spoke of identifying the student's level and expectations. The renal dialysis educator and the day oncology educator discussed how they prepared for the first group of students by investigating other similar units and 
seeing how they organised the students. The renal dialysis educator explained 'So I had a look at what other units do with students and developed a little plan'.

The registered nurses explained how their preparation related to understanding the level of the students.

I've had them loads of times before [in general ward areas], so I just checked what they actually needed to be doing at that time. ... the main thing is to find out what's expected of them and what level they should be at. RN day oncology

The different knowledge required in speciality areas was another finding from the analysis. The registered nurses described these differences particularly in relation to equipment used and medications and their administration. Some of these aspects overwhelmed the students.

I think it initially overwhelms them but I find RNs get overwhelmed by this speciality as well. ... Apprehension of not having seen it before, overridden by the excitement of, "we're going to be able to do a portacath access". RN day oncology

The renal dialysis registered nurses spoke of the knowledge required for setting up the renal dialysis machines. The students commented they felt like they were in a different world 'it's a new thing and you are invading their domain ... importance of the machinery'.

The links to evidence based theory that students developed from these areas was discussed by the students. The students in the renal dialysis area spoke of linking the patho-physiology of the renal system to the patient 'seeing it in a placement just sinks it in, whereas learning it in patho and anatomy just, there 's no realism there'. The students in day oncology explained that they learned more about cancer as a disease and about the holistic care of patients.

Oncology is really interesting, just understanding the different cancer, how every part of your body is affected, the different cancer, treatments and effects, ... I thought I had a good understanding of oncology ... it just blows your mind actually, so this actually gave us an idea of what oncology is all about. Student day oncology

Although these areas were often overwhelming for the student nurses, they gained knowledge and understanding of renal dialysis and oncology over the four week placement.

\section{Team work and being included}


Inclusion in the team was mainly described by the students although the registered nurses spoke of enjoying the students and how they were included. The team work of nurses was described by all the students. They described this as a positive aspect of working with the nurses in these specialty areas.

It looks like they got on well as a team. ... if somebody was struggling, somebody else always helped, there was never that 'oh, it's not my patient' or 'I'm too busy'. It was a real team. Student renal dialysis

Students also described being included in the team, which was not something they had experienced on previous ward placements. One student in renal dialysis summed it up with this comment 'They made us feel like part of the team as well, by not treating us like students'. Sometimes the students stated they felt like they were intruding in the registered nurses interactions with the patients. This was particularly identified by students in the day oncology area. However they described the learning experience as excellent.

Like if you had a patient and they'd be getting upset, you'd be like should I leave and just let the nurse have a conversation? But it was good to see the interaction; that was excellent. Student day oncology

The registered nurses described how they enjoyed working with the students, including the students in their work load and how it was good to be in a teaching role. The following comments reflect the registered nurses response to student placement, although this did depend on the personality of the students.

'Yeah it's been nice having students again' RN 1 Renal dialysis

'Just got to manage work load, take into consideration you are slowing down' RN 2 Day oncology

'I'm looking forward to them coming again next year because I want to get it right; I want to really help these people.' RN 2 day oncology

'Yeah, some did take to it better and I think some RNs take to it better too, it's a personality thing, I think. Some are a little bit more proactive in finding work to do but that's just a personality thing' RN 3 renal dialysis

The culture of registered nurses working within these speciality areas was highly regarded by the students and they valued seeing this type of team work and patient care in their last clinical placements as a student nurse. 


\section{Customising learning needs}

The student learning objectives from these speciality placements caused some concern for both students and registered nurses. The students spoke of having to change their learning objectives for this placement, 'we tailored them [learning objectives] for this place', 'hard area to meet learning objectives that are set by the uni'. Students changed specific learning objectives to suit the area, such as confidence with renal dialysis machines or learning basic medications for chemotherapy. The students were happy to learn new procedures and patient care, and saw this as them achieving the goals of the placement. However the registered nurses wanted a more concrete assessment of students.

I want to know what sort of guidelines, sorry, objectives that they're [students] wanting to do in placement ... I think they are going to need something, even a workbook, we used to have workbooks'. RN renal dialysis

Other comments related to getting students to identifying learning objectives and expectations early in the placement, so the best student outcome could be achieved.

The registered nurses also discussed the need for closer contact with the university to debrief the students. They indicated that they had difficulty with this aspect of the placement due to both workload and not having close rapport with the students.

I think one of the things is that maybe support from the university, even just to call in and say 'how are you going?' like physically seeing students, I think they seem to get so overwhelmed. RN day oncology

The clinical placements in day oncology and renal dialysis provided students with an insight into these normally closed areas, increased their assessment and communication skills, and gave them knowledge of this type of clinical area. The registered nurses described benefits for the students from the placement. One renal dialysis RN explains, 'I think they walked away with a bit of confidence, they left with a high opinion of dialysis which is good because they might want to come to this area.' The students' comments reflected the benefits they identified; learning communication and assessment skills and seeing excellence in team work. An interesting comment from several of the registered nurses was the pressure they felt to 'get the student ready to graduate'. The student nurses were completing their final clinical placement prior to completion of their Bachelor of Nursing and the registered nurses 
commented it was hard to assess students against general ward expectations in these speciality areas.

\section{DISCUSSION}

The analysis revealed that speciality clinical areas were beneficial to undergraduate students, providing a link between theory and practice. The clinical placement also provided students with an insight into these speciality clinical areas not previously available. The students were included in a unique type of nursing, one in which registered nurses work as a team and provide holistic nursing care for oncology and renal patients.

The evaluation explored the student experience, highlighting the need to provide them with information about the type of patient care and procedures occurring in these areas prior to placement. This would increase the students' understanding and ability to achieve good learning outcomes. The registered nurses and the students explained closer support by the university would be beneficial in achieving learning outcomes. Previous research has suggested similar recommendations to provide an appropriate level of learning support (Levett-Jones, Fahy, Parsons, \& Mitchell, 2006; Luhanga, Dickieson, \& Mossey, 2010; Wade \& Hayes, 2010).

The findings from this study are consistent with previous research, which has found effective student facilitation is both time consuming and personally demanding (Brammer, 2008; Luhanga, et al., 2010). The registered nurses involved in the study identified that students slowed them down. Due to the extra time required to explain procedures and the time required to allow students to work at their own pace. This is similar to findings from general ward areas (Brammer, 2008) however in day oncology and renal dialysis procedures need to be kept to a certain time frames to allow for patient appointments. At times this influenced the amount of student involvement. The personal nature of teaching students was noted by registered nurses, with them describing how the personality of the student influenced their connection and teaching. Another consideration was the assessment and support of student nurses so close to them becoming registered nurses. Some registered nurses stated that they felt pressure to ensure the student was at the appropriate level for registration. These findings are similar to those from previous research exploring supporting student transition to graduate nurse, which highlighted that registered nurses are not always prepared for the nature of clinical teaching (Brammer, 2008; Luhanga, et al., 2010; Romyn, et al., 2009). A possible 
solution to reduce the burden of student facilitation would be to provide specific pre-brief information for the student to increase their knowledge and understanding of the area. The concerns of student's assessment can be improved with better support and collaboration from the academics. This collaboration could be beneficial to both areas if the information and expertise from the speciality areas is utilised in the university setting in the way of guest lectures, thus building connections between theory and clinical.

This evaluation identified several benefits of the speciality placement, mainly relating to benefits for students. However the registered nurses also reported personal gains. Benefits for the students related to linking theory and practice for the renal and oncology patients, which the students described as different from the normal ward areas. This has been identified previously in research exploring community placements where new learning objectives needed to be established (Wade \& Hayes, 2010). Wade and Hayes (2010) reported that benefits to the students were the understanding of community nursing. The registered nurses role and experience in preparing the future generation of nurses was similar to previous research (Brammer, 2008; Luhanga, et al., 2010). In particular, the analysis revealed that the registered nurses discussed enjoying working with the students, getting back to basics with the students and being part of the students' progression to registration.

Another benefit of the specialty placement was the connection between registered nurses and other team members. The students discussed feeling included in the team. The registered nurses reflected that they did have a good team and were proud that the students had noticed this. The registered nurses also stated that they had a desire to help the students understand their work and grow into registered nurses. The students commented about the skills of the oncology and renal dialysis registered nurses, specifically their assessment and communication skills. Although previous research has not explored the skills of speciality area nurses in relation to teaching student nurses, the expert skills of registered nurses have been noted in previous research (Fukui, et al., 2009; Gambles, et al., 2003; Turner, Clavarino, Yates, Hargraves, \& Connors, 2007).

There are some limitations to the study although the information builds on previous knowledge exploring student nurse's clinical placement experience. In keeping with the nature of an exploratory study there is no intent to generalise the findings of this study rather the intent is to produce credible findings (Sandelowski, 1993). While the number of 
participants in this study was small it is feasible that students in similar settings will experience comparable issues. The registered nurses all offered to work with the students and hence the comments may reflect a positive relationship with the student. The students also asked to go to these speciality areas so comments may also reflect their interest in these areas.

\section{CONCLUSION}

This study completed an evaluation of a four week speciality clinical placement for $3^{\text {rd }}$ year student nurses identifying the benefits and areas for improvement. The themes from the students and registered nurses related to meeting learning objectives from the placement, key themes were knowledge and preparedness for specialist placement, team work and being included and customising learning needs. Although speciality areas are relatively new in providing clinical placement this evaluation identified several benefits including increasing the students understanding of these areas, development of holistic care including assessment, communication and family inclusive care, all of which increase the graduates employability.

\section{IMPLICATIONS FOR CLINICAL PRACTICE}

This evaluation of clinical placement highlighted a need to tailor the information and learning objectives to suit the speciality areas with an aim to develop clinical preparedness for students in these areas. The university course conveners should provide student debrief and assessment information for the registered nurses thereby enhancing student learning objectives (Levett-Jones \& Bourgeois, 2011).

- Pre-brief information specific to the speciality area provided to the students prior to commencement of placement

- Layered learning objectives for the student to cover during the placement for example beginning level competencies to higher level as the students master specific skills for the area.

- Student debrief provided specific to the clinical area

- Collaboration between clinical area and academics to provide support for students assessment and preparation for clinical placement 


\section{RERERENCE LIST}

. Australian Nursing and Midwifery Council (2012, January 2006). Competency Standards 'National competency standards for the registered nurse' 4th. Retrieved 01/08, 2012, from http://www.anmc.org.au

Beecroft, P. C., Santner, S., Lacy, M. L., Kunzman, L., \& Dorey, F. (2006). New graduate nurses' perceptions of mentoring: six-year programme evaluation. Journal of Advanced Nursing, 55(6), 736-747. doi: 10.1111/j.1365-2648.2006.03964.x

Benner, P., Sutphen, M., Leonard, V., \& Day, L. (2010). Educating Nurses San Francisco Jossey-Bass.

Brammer, J., D. (2008). RN as gatekeeper: gatekeeping as monitoring and supervision. Journal of Clinical Nursing, 17, 1868-1876. Retrieved from doi:10.1111/j.13652702.2008.02376.x

Braun, V., \& Clarke, V. (2006). Using thematic analysis in psychology. Qualitative Research in Psychology, 3, 77-101.

Calpin-Davies, P., J. (2003). Delivering a quality clinical experience means abandoning placments. Nurse Education in Practice, 3(2), 59-60.

Edwards, H., Smith, S., Courtney, M., Finlayson, K., \& Chapman, H. (2004). The impact of clinical placement location on nursing students' competence and preparedness for practice. Nurse Education Today, 24(4), 248-255. doi: 10.1016/j.nedt.2004.01.003

Fukui, S., Ogawa, K., Ohtsuka, M., \& Fukui, N. (2009). Effect of communication skills training on nurses' detection of patients' distress ad related factors after cancer diagnosis: a randomized study Psycho-Oncology, 18(5), 1156-1164. doi: 10.1002/pon.1429

Gambles, M., Wilkinson, S., M, \& Dissanayake, C. (2003). What are you like? Cancer Nursing, 26(2), 97-104.

Grbich, C. (1999). Qualitative Research in Health an Introduction. St. Leonards: Allen \& Unwin.

Levett-Jones, T. (2005). Self-directed learning: Implications and limitations for undergraduate nursing education. Nurse Education Today, 25(5), 363-368. doi: 10.1016/j.nedt.2005.03.003

Levett-Jones, T., \& Bourgeois, S. (2011). The clinical placement: An essential guide for nursing students. Sydney: Elsevier.

Levett-Jones, T., Fahy, K., Parsons, K., \& Mitchell, A. (2006). Enhancing nursing students clinical placement experiences: A quality improvement project Contemporary Nurse 23(1), 58-71.

Luhanga, F., L, Dickieson, P., \& Mossey, S., D. (2010). Preceptor preparation: An investment in the future generation of nurses. International Journal of Nursing Education Scholarship, 7(1), 1-18. doi: 10.2202/1548-923X.1940

Miles, M., B, \& Huberman, A., M. (1994). Qualitative data analysis: An expanded sourcebook ( 2 ed.). Thousand Oaks CA: SAGE.

Neill, J., \& Taylor, K. (2002). Undergraduate Nursing Students' Clinical Experiences in Rural and Remote Areas: Recruitment Implications. Australian Journal of Rural Health, 10(5), 239. doi: 10.1046/j.1440-1584.2002.00482.x

Newton, J. M., \& McKenna, L. (2008). The transitional journey through the graduate year: a focus group study. International Journal of Nursing Studies, 44(7), 1231-1237. doi: 10.1016/j.ijnurstu.2006.05.017

Romyn, D., Linton, N., Giblin, C., Hendrickson, B., Limacher, L., Murray, C., Nordstrom, P., Thauberger, G., Vosburgh, D., Vye-Rogers, L., Weidner, A., \& Zimmel, C., M. 
(2009). Successful transition of the new graduate nurse. International Journal of Nursing Education Scholarship, 6(1), 1-17. doi: 10.2202/1548-923X.1802

Ryan, G., W, \& Bernard, H., R. (2003). Techniques to identify themes. Field Methods, 15(1), 85-109. doi: 10.1177/1525822X02239569

Sandelowski, M. (1993). Rigor or rigor mortis: the problem in qualitative research revisited. Advances in Nursing Science, 16(2), 1-8.

Silverman, D. (Ed.). (2003). Qualitative Research Theory, Method and Practice. London: SAGE Publications Ltd.

Turner, J., Clavarino, A., Yates, P., Hargraves, M., \& Connors, V. (2007). Oncology nurses' perceptions of their supportive care for parents with advanced cancer: challenges and educational needs Psycho-Oncology, 16(2), 149-157. doi: 10.1002/pon.1106

Wade, G., H, \& Hayes, E. (2010). Challenges and opportunities associaed with preceptored community health clinical expereinces. Public Health Nursing, 27(5), 459-467. doi: 10.11111/j.1525-1446.2010.00879.x

Received $10^{\text {th }}$ March $2012 \quad$ Accepted $14^{\text {th }}$ May 2012

Table 1 Interview questions

\begin{tabular}{|l|l|}
\hline Student questions & Registered nurse questions \\
\hline $\begin{array}{l}\text { Can you explain how you felt when you } \\
\text { arrived on the first day? }\end{array}$ & $\begin{array}{l}\text { How did you prepare yourself to be able } \\
\text { to work with undergraduate students in } \\
\text { this area? }\end{array}$ \\
\hline $\begin{array}{l}\text { Were you prepared for this type of } \\
\text { placement area? }\end{array}$ & $\begin{array}{l}\text { Would it have been useful to be provided } \\
\text { with more information about working } \\
\text { with undergraduate students and their } \\
\text { level of knowledge and skills? }\end{array}$ \\
\hline $\begin{array}{l}\text { How did you find this placement, and } \\
\text { working in this area? }\end{array}$ & $\begin{array}{l}\text { Can you explain how you found working } \\
\text { with the students on this placement? }\end{array}$ \\
\hline $\begin{array}{l}\text { Can you explain how you met learning } \\
\text { objectives? }\end{array}$ & $\begin{array}{l}\text { Did you find you had an understanding of } \\
\text { the students learning objectives and how } \\
\text { you can assist the student to meet these } \\
\text { objectives? }\end{array}$ \\
\hline $\begin{array}{l}\text { Can you provide any suggestions of } \\
\text { how this placement can be improved? }\end{array}$ & $\begin{array}{l}\text { In the future is there anything the } \\
\text { university could do to assist you working } \\
\text { with the student? }\end{array}$ \\
\hline
\end{tabular}

Reviewers comments addressed.

\begin{tabular}{|l|l|}
\hline Reviewer comments & Changes to paper \\
\hline
\end{tabular}




\begin{tabular}{|c|c|}
\hline $\begin{array}{l}\text { Does the paper require } \\
\text { expansion?: } \\
\text { YES More information of the } \\
\text { flow of students into the } \\
\text { study } \\
\text { I would like to see more } \\
\text { information on the flow of } \\
\text { the nurses into the study. } \\
\text { How many were asked, how } \\
\text { many refused and what were } \\
\text { the reasons? Was being too } \\
\text { busy the reason given for all? } \\
\text { How many? The sample size } \\
\text { is small so it is very } \\
\text { important to know who we } \\
\text { are dealing with. }\end{array}$ & $\begin{array}{l}\text { A convenience sample of student nurses completing four } \\
\text { week clinical placement in a renal dialysis unit and an } \\
\text { ambulatory day oncology unit were invited to participate in } \\
\text { the evaluation }(\mathrm{N}=10) \text {. Students were selected to complete } \\
\text { clinical placement in these areas, day oncology and renal } \\
\text { dialysis in two ways, student preference and good academic } \\
\text { merit. Semi-structured interviews were conducted with } \\
\text { student nurses }(\mathrm{n}=7) \text { who volunteered to participate in the } \\
\text { study. Three students declined to participate explaining they } \\
\text { were too busy to come in for the interview. }\end{array}$ \\
\hline $\begin{array}{l}\text { Some discussion of what to } \\
\text { do next, since the results tend } \\
\text { to confirm previous studies }\end{array}$ & $\begin{array}{l}\text { This evaluation of clinical placement highlighted a need to } \\
\text { tailor the information and learning objectives to suit the } \\
\text { speciality areas with an aim to develop clinical preparedness } \\
\text { for students in these areas. The university course conveners } \\
\text { should provide student debrief and assessment information } \\
\text { for the registered nurses thereby enhancing student learning } \\
\text { objectives (Levett-Jones \& Bourgeois, 2011). } \\
\text { - Pre-brief information specific to the speciality area } \\
\text { provided to the students prior to commencement of } \\
\text { placement } \\
\text { - Layered learning objectives for the student to cover } \\
\text { during the placement for example beginning level } \\
\text { competencies to higher level as the students master } \\
\text { specific skills for the area. } \\
\text { Student debrief provided specific to the clinical area } \\
\text { Collaboration between clinical area and academics to } \\
\text { provide support for students assessment and } \\
\text { preparation for clinical placement }\end{array}$ \\
\hline
\end{tabular}




\begin{tabular}{|c|c|}
\hline $\begin{array}{l}\text { I would like a statement } \\
\text { discussing if you believe the } \\
\text { results obtained here might be } \\
\text { somehow slanted by the fact } \\
\text { that this was an experiment. } \\
\text { It is not clear to me how these } \\
\text { results address the reason } \\
\text { why these areas generally } \\
\text { exclude nurses now (as } \\
\text { presented in the abstract). In } \\
\text { fact don't these results } \\
\text { somewhat substantiate those } \\
\text { reasons as being somewhat } \\
\text { valid? Page } 6 \text { "The students } \\
\text { identified that they lacked } \\
\text { knowledge and preparation } \\
\text { for these areas." "... students } \\
\text { slowed them down". }\end{array}$ & $\begin{array}{l}\text { Although speciality areas are relatively new in providing } \\
\text { clinical placement this evaluation identified several benefits } \\
\text { including increasing the students understanding of these } \\
\text { areas, development of holistic care including assessment, } \\
\text { communication and family inclusive care, all of which } \\
\text { increase the graduates employability. }\end{array}$ \\
\hline $\begin{array}{l}\text { These results (from a pilot } \\
\text { study) tended to confirm prior } \\
\text { conceptions for both students } \\
\text { and nurse teachers. One } \\
\text { useful benefit from this paper } \\
\text { could be achieved by having } \\
\text { the authors suggest possible } \\
\text { ways to address these issues } \\
\text { as well a proposing some } \\
\text { possible ways to run } \\
\text { additional experiments to } \\
\text { evaluate possible solutions. } \\
\text { The results are somewhat } \\
\text { expected. The paper would } \\
\text { be more interesting if the } \\
\text { authors entered in a } \\
\text { discussion of what (if } \\
\text { anything) should be done } \\
\text { next. }\end{array}$ & $\begin{array}{l}\text { A possible solution to reduce the burden of student } \\
\text { facilitation would be to provide specific pre-brief } \\
\text { information for the student to increase their knowledge and } \\
\text { understanding of the area. The concerns of student's } \\
\text { assessment can be improved with better support and } \\
\text { collaboration from the academics. This collaboration could } \\
\text { be beneficial to both areas if the information and expertise } \\
\text { from the speciality areas is utilised in the university setting in } \\
\text { the way of guest lectures, thus building connections between } \\
\text { theory and clinical. }\end{array}$ \\
\hline
\end{tabular}

